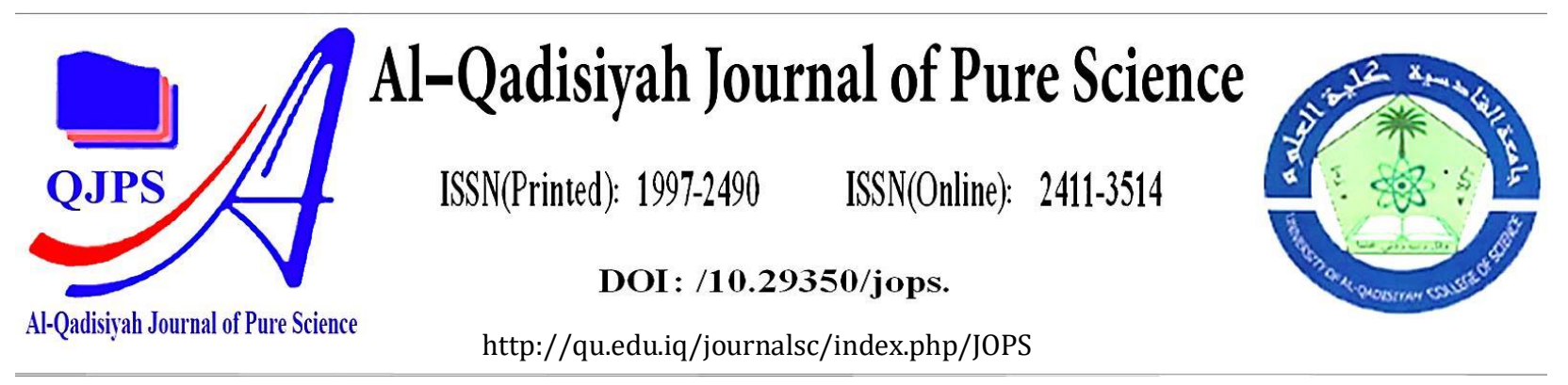

\title{
Synthesis and Diagnosis New Metallotropic LCs from Organotin (IV) Complex
}

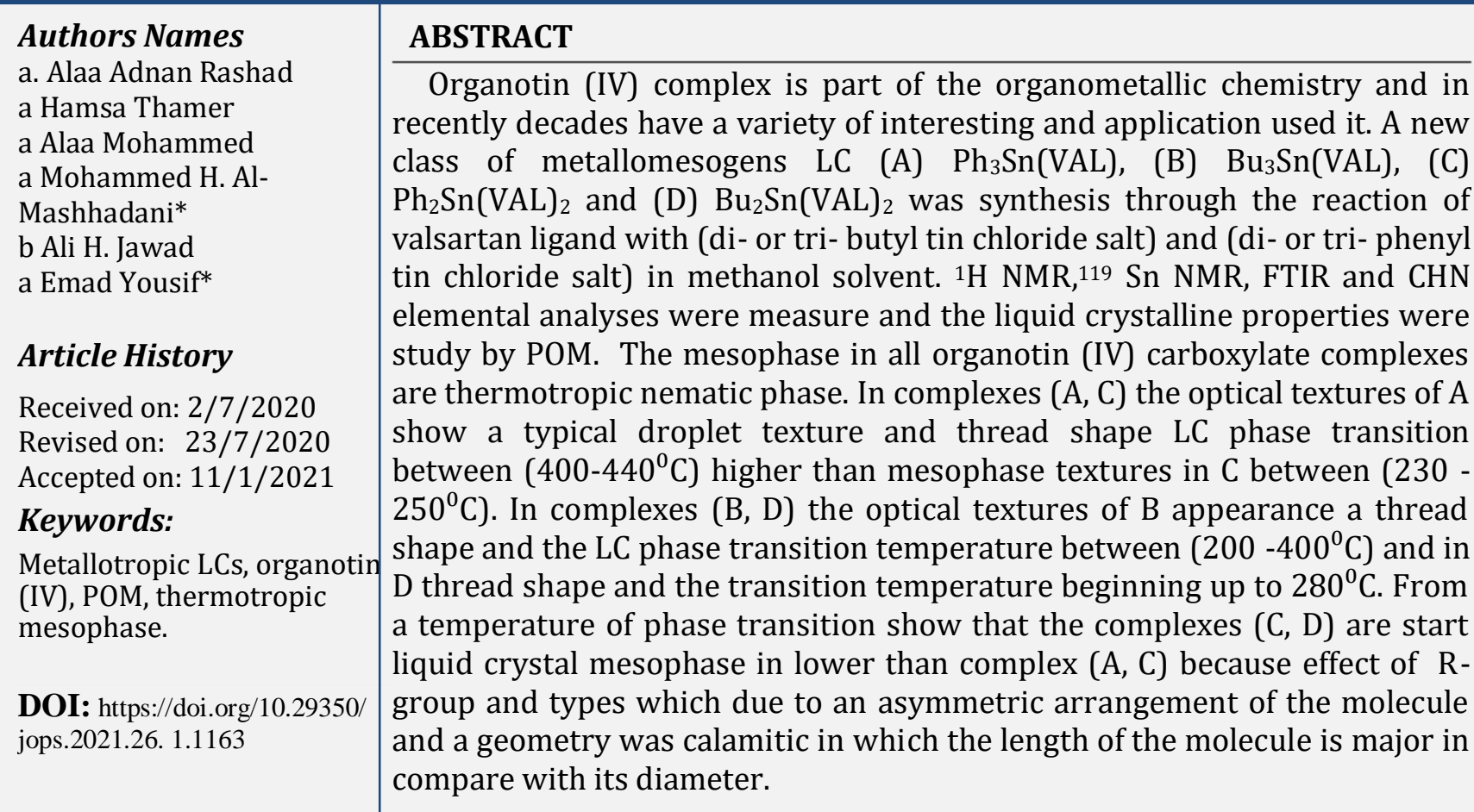

\section{Introduction}

Organotin (IV) compounds are part of the organometallic chemistry and its form as a tin metal with tetraorgano derivatives substituents. Organotin (IV) complex have a variety of interesting and supramolecular structures according to the many parameters such as the type of ligand [1]. Tin

a Department of Chemistry, College of Science, Al-Nahrain University, P.0. Box: 64021, Baghdad, Iraq, E-Mail: silverarch2016@gmail.com; alaaalqaycy7@gmail.com; dahan62@yahoo.com; mo_chemical@yahoo.com; emad_yousif@hotmail.com

b Faculty of Applied Sciences, Universiti Teknologi MARA, Shah Alam, Selangor, Malaysia, E-Mail: ali288@uitm.edu.my 
coordination geometry is preferences, tin-R groups, and metal-to-ligand molar ratio. Moreover, intermolecular forces as the hydrogen bonding interaction, these structure properties give the strength and direction to compound [2-3]. In recent decades, organotin (IV) compounds have very interested and wide used in extensive applications like biological as antibacterial, and antitumor agents [4-7], chemistry and industrial [8-10], and agricultural [11] because their structural and coordination and ligand used. Liquid crystal is an intermediate state between solids and liquids state; they possess characteristics fluidity, formation and coalescence of droplets like a liquid and flexibility, arrangement of molecules in one or more directions, anisotropy of optical, electrical, and magnetic properties like a crystalline solid [12-16].

Liquid crystals typical have many mesophases depending on the arrangement of the molecules in directions (n); liquid crystals phase are characteristic into cholesterics, nematic, smectics, and columnar and molecules are designate mesogen. Liquid crystals phases can split into thermotropic, lyotropic and metallotropic. In Thermotropic and lyotropic liquid crystals consist mostly of organic molecules, and may contain a few minerals in its structure, LCs transitions phase in Thermotropic LCs appear as a function of change in temperature while in Lyotropic LCs appear as a function of both the temperature and the concentration of the LC molecules in a solvent. Metallotropic LCs are consist of both organic and inorganic molecules; their LCs transition phase depends not only on the temperature and on the concentration of solvent like Thermotropic LCs and Lyotropic LCs, but also on the organic - inorganic composition ratio [17-19].

Metallotropic LCs (metallomesogens) based on metal complex that LCs phase prepared and can exhibit as thermotropic by coordination or ionic complexes between organic and inorganic molecules. Metallotropic LCs have interesting properties related to metal ions, such as luminescence, magnetism, redox properties. [20, 21]. The thermotropic liquid crystals have unique electro optical properties [2226] that led to used it in various applications (LCD, molecular sensors and detectors, optical switches, spatial light modulator, etc.) [27-28]. The molecules of liquid crystalline phases have a specific shape; typical rod-like or disk-like molecules, the most form in nematic and smectic phases are rod-like molecules or rod-like molecular aggregates [30].

Liquid crystals have been study for fundamental science and research in many fields such as chemistry, physics, medicine, and engineering applications, In addition, a nanostructured liquid 
crystalline compound by dispersion of liquid crystal with nanostructure compound to enhancement its properties in the field of used [31-35].

Valsartan is a white fine powder. It is soluble in ethanol and methanol and slightly soluble in water, it has an empirical formula of $\mathrm{C}_{24} \mathrm{H}_{29} \mathrm{~N}_{5} \mathrm{O}_{3}$ and a molecular weight of $435.5 \mathrm{~g} / \mathrm{mol}$ [36,37], Valsartan was patented in 1990, and came into medical use in 1996 [38]. The aim of this work includes studying a new class of metallomesogens based on organotin (IV) halide compound with valsartan ligand was prepared organotin (IV) carboxylates complexes and the liquid crystalline properties of the complexes were study by a FTIR, ${ }^{1} \mathrm{H}$ NMR, ${ }^{119} \mathrm{Sn}$ NMR , CHN and polarizing optical microscopy (POM).

\section{Experimental}

\subsection{Reagents and chemicals}

Chemical material organotin (IV) salt, valsartan, and solvents were supply by Merck (Gillingham, UK) without any further purification.

\subsection{Characterization Methods}

Characteristic of organotin (IV) complexes prepared by FTIR, ${ }^{1} \mathrm{H}$ NMR, ${ }^{119} \mathrm{Sn}$ NMR, CHN are measured. The optical phase texture of organotin (IV) complexes were estimate by polarizing optical light microscopy (POM), using MEIJI microscope equipped with INSTEC hot stage and central processor controller mK1000 and connected with Lumenera color video camera.

\subsection{Preparation of organotin (IV) carboxylates complexes}

Four organotin (IV) carboxylates complexes, (A) $\mathrm{Ph}_{3} \mathrm{Sn}(\mathrm{VAL})$, (B) $\mathrm{Bu}_{3} \mathrm{Sn}(\mathrm{VAL}),(\mathrm{C}) \mathrm{Ph}_{2} \mathrm{Sn}(\mathrm{VAL})_{2}$ and (D) $\mathrm{Bu}_{2} \mathrm{Sn}(\mathrm{VAL})_{2}$ ) were prepared from reaction of valsartan ligand with organotin (IV) salt in methanol solvent in different ratio, 1:1 for $\mathrm{A}, \mathrm{C}$ complex and ratio 1:2 for $\mathrm{B}, \mathrm{D}$ complex as show in a previous work [36]. Scheme (1), shows the organotin (IV) complexes synthesis and their suggested structure. 


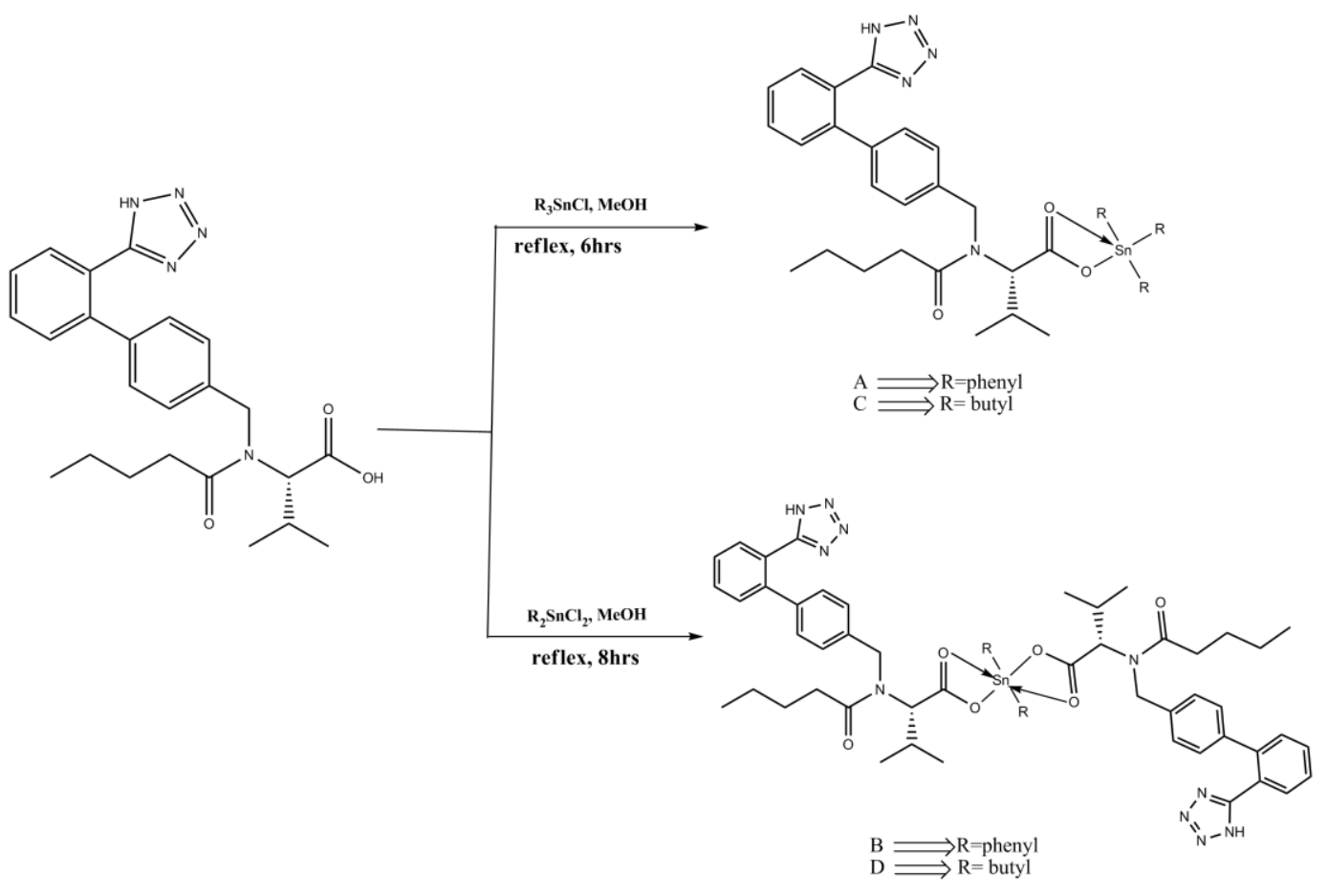

Scheme 1. Synthesis of organotin (IV) complexes.

\section{Results and Discussions}

\subsection{Characterization of organotin (IV) complexes}

A synthesis of a novel organotin (IV) complexes (A-D) through the reaction of valsartan ligand with (di- or tri- butyl tin chloride salt) and (di- or tri- phenyl tin chloride salt) in methanol as shown in (Scheme 1) and the complexes color appetence between off-white to white depended on the salt used [36]. To prove the new organotin (IV) complexes form ${ }^{1} \mathrm{H}$ NMR, ${ }^{119} \mathrm{Sn}$ NMR, FTIR and CHN elemental analyses was measure and identification a physical properties was obtain in a previous work [36].

\subsection{Liquid Crystalline Properties}

The molecules of new organotin (IV) carboxylate complexes was investigate for their LC phases according to their optical textures by using hot-stage polarizing optical microscopy (POM) for all complexes. The liquid crystalline phase showed by complexes are due to a symmetric arrangement of the molecule and a geometry was calamitic in which the length of the molecule is major in compare with its diameter. 
In organotin (IV) complex (A, C). The mesophase is thermotropic nematic phase. The optical textures of A complex (Figure 1) show a typical droplet texture and the liquid crystalline phase transition temperature start at $400^{\circ} \mathrm{C}$ and thread shape appearance $440^{\circ} \mathrm{C}$. The optical textures of $\mathrm{C}$ complex (Figure 2) show the transition temperature of a mesophase is start at $230^{\circ} \mathrm{C}$ and at $250^{\circ} \mathrm{C}$ thread shape completely form. From a temperature of a mesophase observed that in complex $\mathrm{C}$ mesophase is start and thread shape completely in lower temperature than complex A that occur because the structure of complex composition A which have more phenyl group electron- withdrawing then the electron is continuous in resonance in molecule.
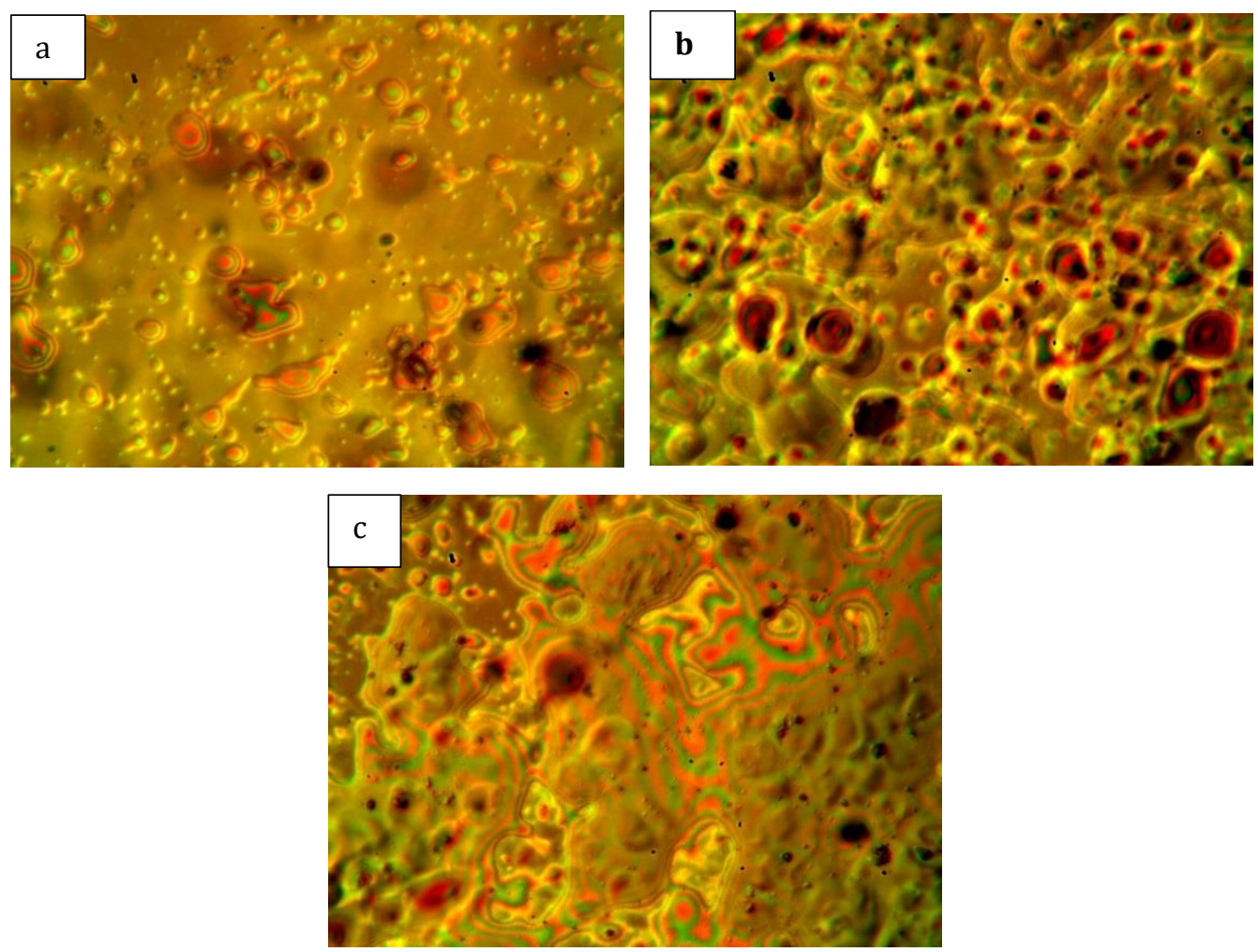

Figure (1): The optical textures of organotin (IV) complexes for A at (a) $400{ }^{\circ} \mathrm{C}$, (b) 430 ${ }^{\circ} \mathrm{C}$ and (c) $440{ }^{\circ} \mathrm{C}$ by hot- stage polarizing optical microscope at $20 x$. 

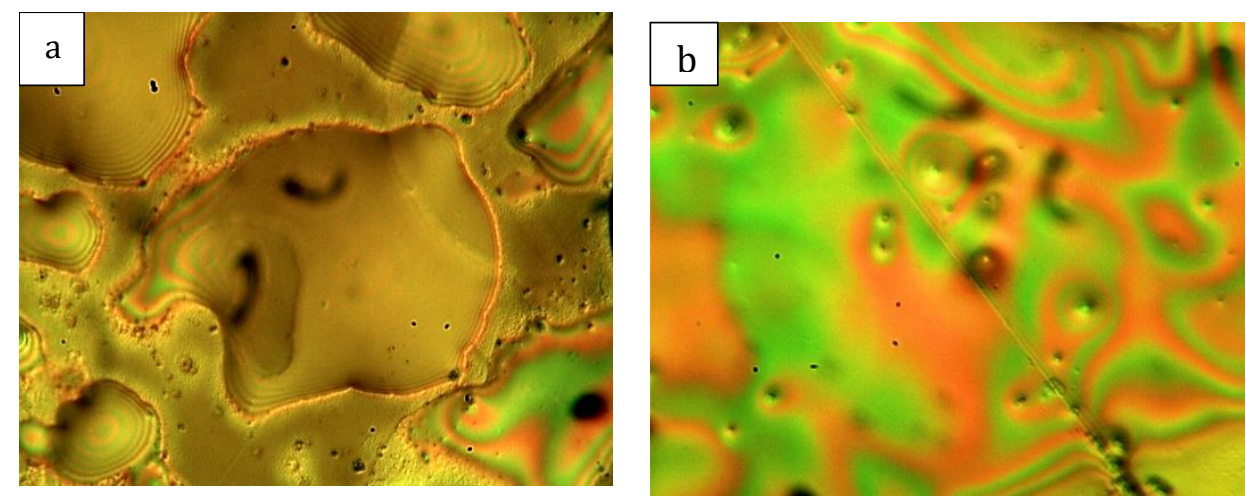

Figure (2): The optical textures of organotin (IV) complexes for $\mathrm{C}$ at (a) $230{ }^{\circ} \mathrm{C}$, (b) 250 ${ }^{\circ} \mathrm{C}$ by hot- stage polarizing optical microscope at $20 x$.

In organotin (IV) complex (B, D). The optical textures of B complex (Figure 3) appearance a thread shape and the liquid crystalline phase transition temperature between $\left(200-400{ }^{\circ} \mathrm{C}\right)$. The optical textures of D complex (Figure 4) show thread shape and the transition temperature up to $280{ }^{\circ} \mathrm{C}$. The transition temperature in B lower than D because it have three butyl group give the structure more rigidity and they are electron-release increase the density of electron on tin metal and the resonance of molecules and the length of molecules lower than D.
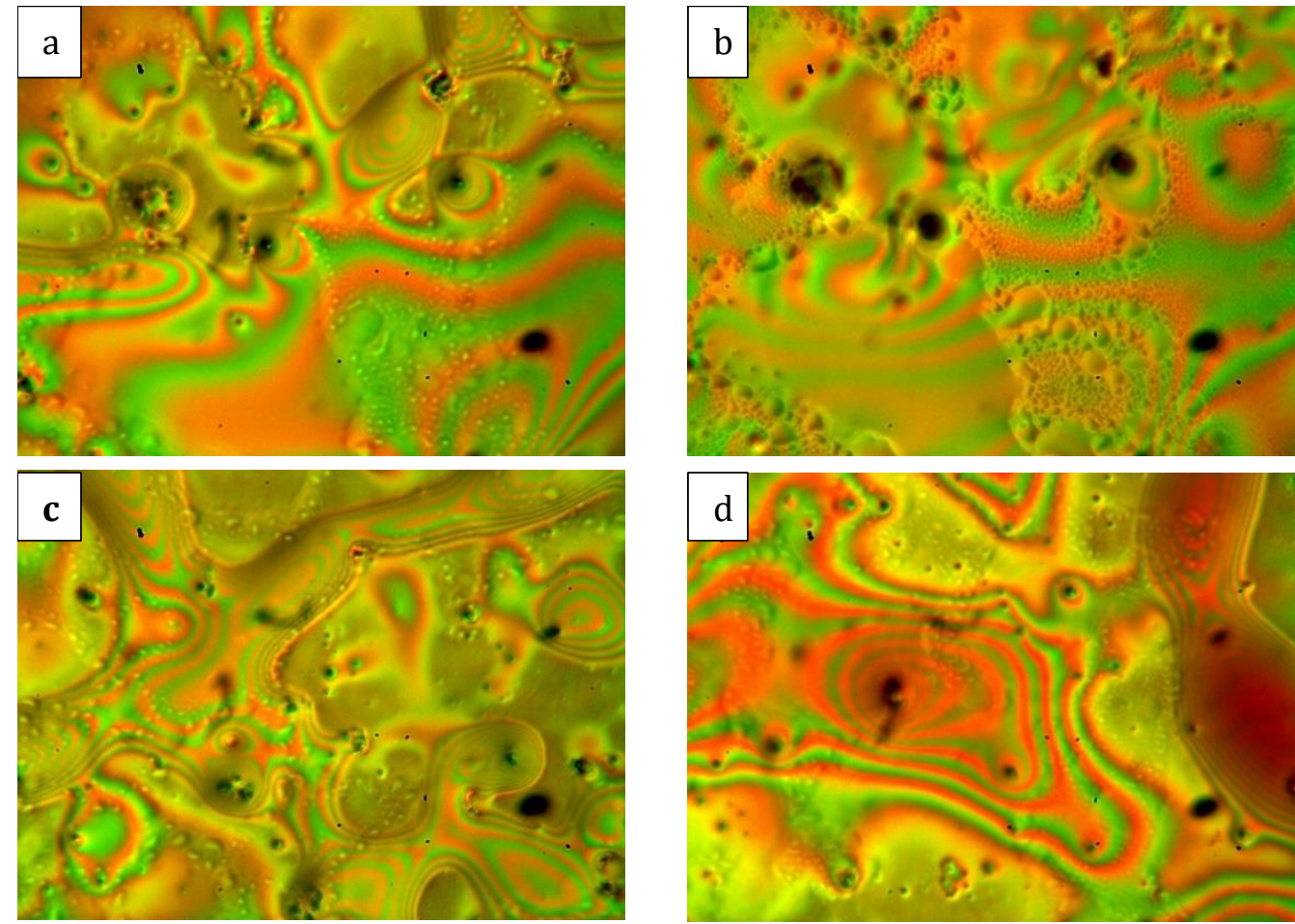

Figure (3): The optical textures of organotin (IV) complexes for $\mathrm{B}$ at (a)200 ${ }^{\circ} \mathrm{C},(\mathrm{b}) 260^{\circ} \mathrm{C}$ , (c) $300{ }^{\circ} \mathrm{C}$ and (d) $400{ }^{\circ} \mathrm{C}$ by hot- stage polarizing optical microscope at $20 x$. 

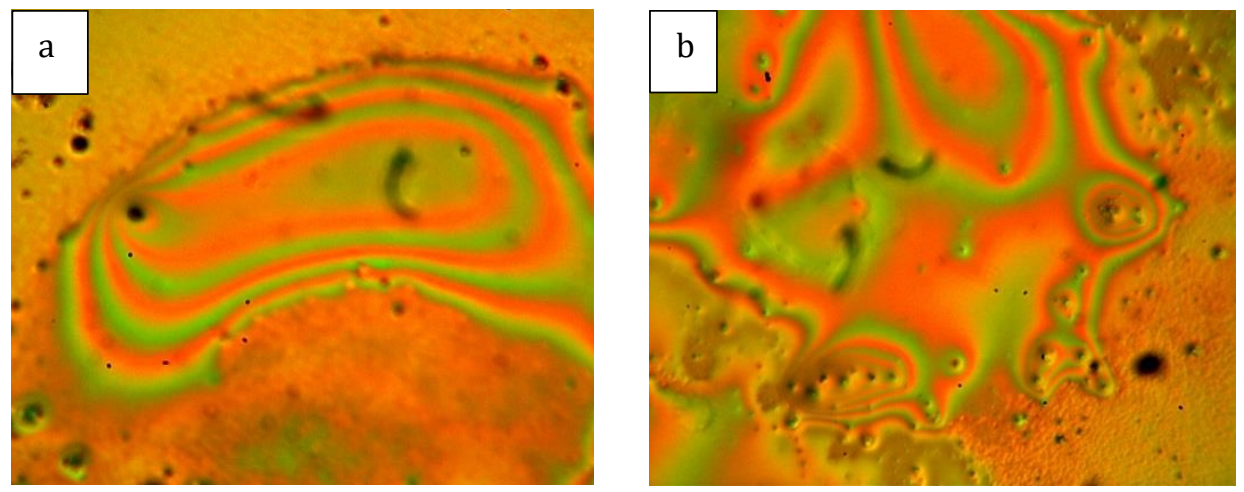

Figure (4): The optical textures of organotin (IV) complexes for $D$ at

(a) $280{ }^{\circ} \mathrm{C}$, (b) $300{ }^{\circ} \mathrm{C}$ by hot- stage polarizing optical microscope at $20 \mathrm{x}$.

\section{Conclusion}

A new class of metallomesogens LC properties were study by polarizing optical microscopy (POM) and show the effected of structure and R-tin group in organotin (IV) carboxylate complex on phase transition. when R-group is alkyl, the increase of number give the more rigidity to the structure then lower phase transition and when R-group is phenyl, the increase give higher phase transition.

\section{Acknowledgments}

This work was works and supported by Department of Chemistry, College of Science, Al-Nahrain University, Baghdad, Iraq.

\section{References}

1. Bufaroosha M., Salih N., Hadi A., Ahmed D. S., Al-mashhadani M. H., Yousif E., The Effect of UV Aging on the Structure of PVC in the Presence of Organotin(IV) Compounds, ANJS, 23 (1), 57 - 61, 2020.

2. Tushar S., Baul B., Masharing C., Ruisi G., Sko R. J., Apek M. H., Vos D., Wolstenholme D. , Linden A., Selfassembly of extended Schiff base amino acetate skeletons,2-\{[(2Z )-(3-hydroxy-1-methyl-2butenylidene $)]$ amino $\}$ phenylpropionateand 2-\{[(E )-1-(2 hydroxyaryl)alkylidene $]$ amino $\}$ phenylpropionateskeletons incorporating organotin(IV) moieties: Synthesis, spectroscopic characterization, crystal structures, and in vitro cytotoxic activity, Journal of Organometallic Chemistry, 692, 4849-4862, 2007.

3. Mohammed S. A., Najim L. H., Al-mashhadani M. H., Ismael M., Hamad B. A., Noaman R., Ibraheem H., Ahmed D. S., Yousif E., Morphological and Photodecomposition Rate Constant Study of PVC Films Doped with Sulfadiazine Tin(IV) Complexes, Science Letters, 14(1), 88-96, 2020. 
4. Sirajuddin M., McKee V., Tariq M., Ali S., Newly designed organotin(IV) carboxylates with peptide linkage: Synthesis, structural elucidation, physicochemical characterizations and pharmacological investigations, European Journal of Medicinal Chemistry, 143, 1903-1918, 1 January 2018.

5. Gholivand K., Rajabi M., Dorosti N., Molaei F., synthesis, structural characterization, density functional theory calculations and biological evaluation of a new organotin(IV) complex containing $\mathrm{N}$-isonicotinyl-N', $\mathrm{N}^{\prime \prime}$-diaryl phosphorictriamide as N-donor ligand, Applied Organometallic chemistry, 29(11), 739-745, November 2015.

6. Arjmand F., Parveen, S., Tabassum S., Pettinari C., Organo-tin antitumour compounds: their present status in drug development and future perspectives, Inorg. Chim. Acta. , 423, 26-37, 2014.

7. Carraher C. E., Roner M. R., Organotin polymers as anticancer and antiviral agents. J. Organomet. Chem., 751, 67-82, 2014.

8. Š̌vec P., Bartoš K., Růžičková Z., Cuř́inová P., Dušek L., Turek J., Proft F. D., Růžička A., C,N-Chelated organotin(IV) azides: synthesis, structure and use within click chemistry, New J. Chem., 40, 5808-5817, 2016.

9. Silva M. A., Santos A. S. S., Santos T. V., Meneghetti M. R., Meneghetti S. M. P., Organotin(IV) compounds with high catalytic activities and selectivities in the glycerolysis of triacylglycerides, Catalysis Science \& Technology, 23, 2017

10. Adeyemi J.O., Onwudiwe D.C., Organotin(IV) Dithiocarbamate Complexes: Chemistry and Biological Activity, Molecules, 23, 2571, 2018

11. George D. A., Organotin Chemistry, Weinheim: Wiley-VCH. , 2nd Edition, 2004. ISBN 978-3-527-31023-4

12. Gennes P. G. , Prost J., the Physics of Liquid Crystals, Clarendon, Oxford, , 2nd Edition, 1993.

13. Stewart I. W., the Static and Dynamic Continuum Theory of Liquid Crystals: A Mathematical Introduction ,Taylor \& Francis, London, 2004.

14. Chaikin P. M., Lubensky T. C., Principles of condensed matter physics, Cambridge University Press, Cambridge, 1995.

15. Chandrasekhar S., Liquid Crystals, Cambridge University Press, Cambridge, 2nd ed., 1992.

16. Stephen M. J., Straley J. P., Physics of liquid crystals, Rev. Mod. Phys., 46, 617, 1974.

17. Dierking I., Textures of Liquid Crystals, Weinheim: Wiley-VCH, 2003, ISBN 978-3-527-30725-8.

18. Patrick D., Jean C. P. G., Mineral Liquid Crystals from Self-Assembly of Anisotropic Nanosystems, Top Curr Chem, 226, 119, 2003. doi:10.1007/b10827.

19. Paineau E., Philippe A. M., Antonova K., Bihannic I., Davidson P., Dozov I., Gabriel J. C. P., Impéror C. M., Levitz P., Meneau F., Michot L., Liquid-crystalline properties of aqueous suspensions of natural clay nanosheets, Liquid Crystals Reviews, 1 (2), 110, 2013. doi:10.1080/21680396.2013.842130.

20. Date R. W., Iglesias E. F., Rowe K. E., Elliott J. M., and Bruce D. W., Metallomesogens by ligand design, Dalton Transactions, 10, 1914-1931, 2003.

21. Torroba J., Bruce D. W., Metallomesogens, in Comprehensive Inorganic Chemistry II: From Elements to Applications, Elsevier Ltd., New York, NY, USA, 2nd edition, 2013.

22. Manaila M. D., New grafted ferrite particles/liquid crystal composite under magnetic field, Journal of Magnetism and Magnetic Materials, 452, 343-348, 2017.

23. Gilli J. M., iberge S., and Manaila M. D., New aspect of the voltage/confinement ratio phase diagram for a confined homeotropic cholesteric, Molecular Crystals and Liquid Crystals, 417( 1), 207-213, 2004. 
24. Manaila M. D., Bena R., Albu A. M., Electric and electro-optic investigations on polymer dispersed liquid crystal films, Modern Physics Letters B, 11, 431-440, 1997.

25. Rosu C., Maximean D. M., Kundu S., Almeida P. L., Danila O., Perspectives on the electrically induced properties of electrospun cellulose/liquid crystal devices, Journal of Electrostatics, 69(6), 623-630, 2011.

26. Manaila M. D. and Rosu C., Influence of polarizing electric field on electrical and optical properties of PDLC films, Molecular Crystals and Liquid Crystals, 413( 1), 9-19, 2004.

27. Fleischmann E. K., Zentel R., Liquid-crystalline ordering as a concept in materials science: from semiconductors to stimuli-responsive devices, Angewandte Chemie International Edition, 52( 34), 8810-8827, 2013.

28. Laschat S., Baro A., Steinke N., et al., Discotic liquid crystals: from tailor-made synthesis to plastic electronics, Angewandte Chemie International Edition, 46(26), 4832-4887, 2007.

29. Tschierske C., Development of structural complexity by liquid-crystal self-assembly, Angewandte Chemie International Edition, 52(34), 8828-8878, 2013.

30. Sergey V. P., Vladimir G. C., Dina V. S., Liquid Crystals: Viscous and Elastic Properties in Theory and Applications, Wiley-VCH, 1st Edition, November 2009, ISBN: 978-3-527-40720-0.

31. Lagerwall J.P.F., Scalia G., A new era for liquid crystal research: Applications of liquid crystals in soft matter nano-, bio- and microtechnology, Current Applied Physics, 12(6), 1387-1412, 2012. DOI:10.1016/j.cap.2012.03.019.

32. Körner H, Shiota A, Bunning TJ, Ober CK. Orientation-on-demand thin films: Curing of liquid crystalline networks in an electric fields. Science, 272(5259), 252-255, 1996. DOI: 10.1126/ science.272.5259.252.

33. Hulvat J.F., Stupp S.I., Liquid-Crystal Templating of Conducting Polymers, Angewandte Chemie, 42(7), 778-781, 2003. DOI: 10.1002/anie.200390206.

34. Hentze H.P., Kaler E.W., Polymerization of and within Selforganized Media, Current Opinion in Colloid and Interface Science, 8(2), 164-178, 2003. DOI: 10.1016/ S1359-0294(03)00018-9.

35. Criscione L., Bradley W., Buhlmayer P., Whitebread S., Glazer R., Lloyd P., Mueller P, Gasparo MD. , Valsartan:Preclinical and Clinical Profile of an Antihypertensive Angiotensin-II Antagonist, Cardiovasc Drug Rev, 13(3),230-250, 1995.

36. Yan J., Chen L., Chen S. Electrochemical Behavior of Valsartan and its Determination in Capsules, Colloids Surf B Biointerfaces, 67, 205-209, 2008.

37. Fischer J., Ganellin C.R., Analogue-Based Drug Discovery, John Wiley \& Sons , 1st Edition, 470, 2006, ISBN 9783527607495

38. Mohammed A., El-Hiti G. A., Yousif E., Ahmed A. A.,. Ahmed D. S , Alotaibi M. H., Protection of Poly(Vinyl Chloride) Films against Photodegradation Using Various Valsartan Tin Complexes, Polymers, , 12, 969,2020, doi:10.3390/polym12040969. 